\title{
: : Specification and Use of a Persuasive Serious-Game to Rehabilitate Patients with Dysexecutive Syndrome

CONTEXT

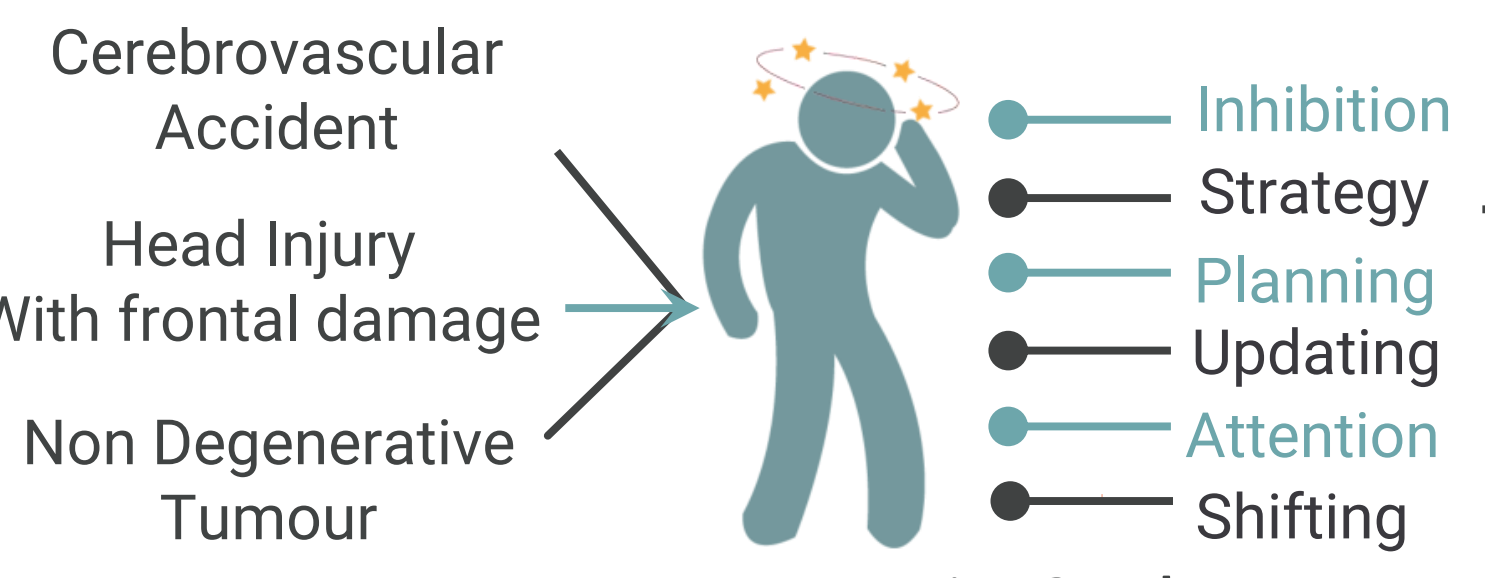

Dysexecutive Syndrome
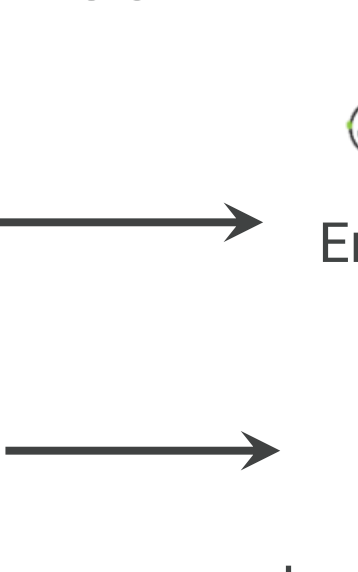

กำ

Emotional

Impact

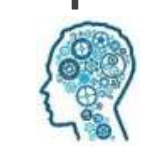

ind

Cognitive Behavioural Consequences

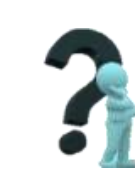

Lack of Autonomy Anosognosia

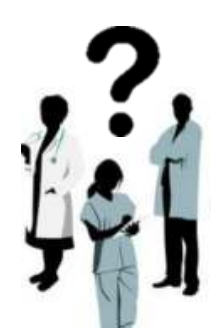

Therapists toöls are limited and specialists are looking for a new way to help the patients to recover their capacities and daily-life

\section{How to reinvent the care offer?
Transferring patients at the heart of their rehabilitation}

A multidisciplinary Research

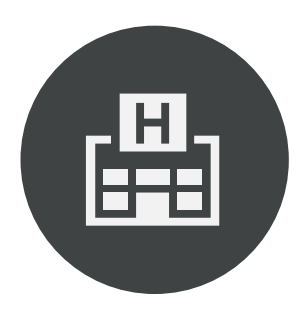

Medical

Specialits

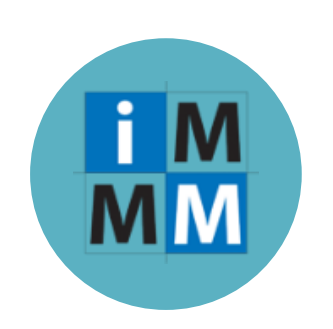

Laboratoire IMSIC Toulon

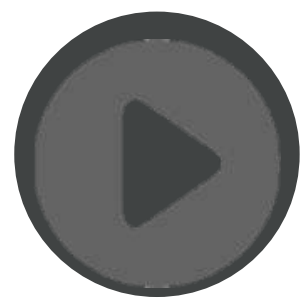

Multimedia Specialists

Device
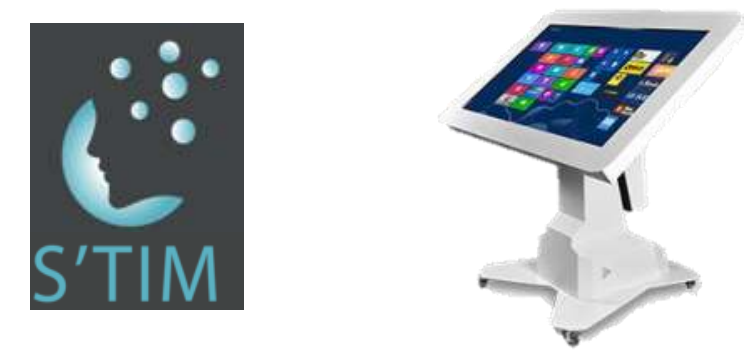

We chose to specify the persasive SeriousGame S'TIM and to use it on an easy-touse robotised touch table of $48^{\prime}$.
Involved functions

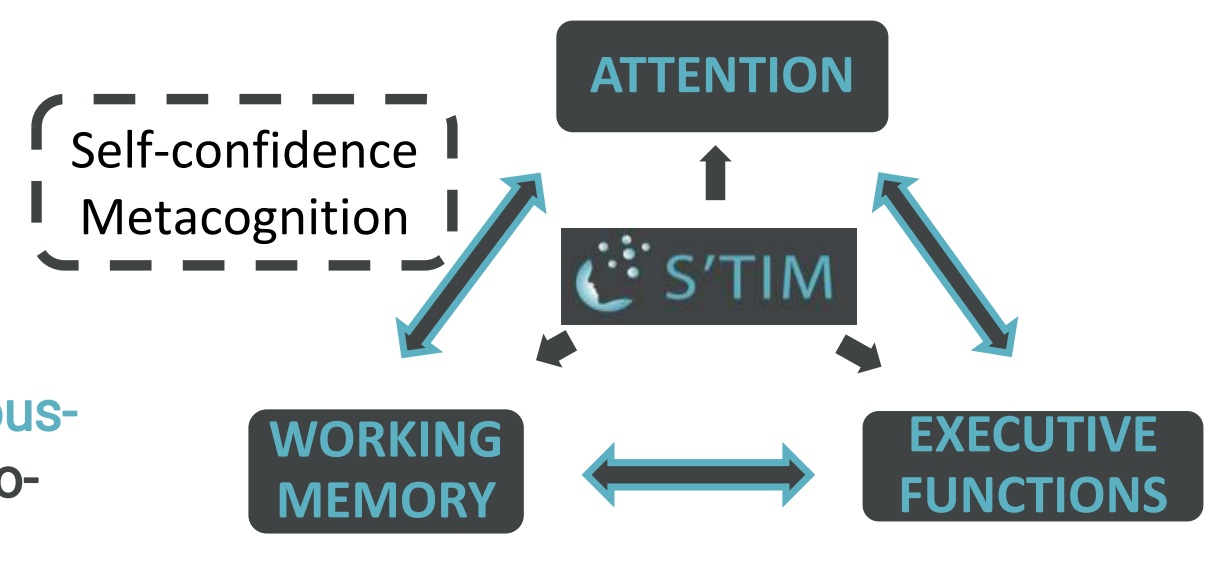

\section{S'TIM Characteristics}
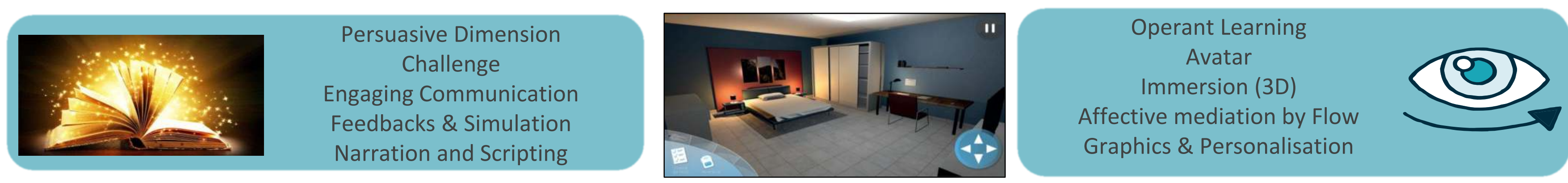

S'TIM Effects

Progressive cognitive mobilization Learning Theory (guidance, mediation) Auto-determination Theory (Motivation)

Aut
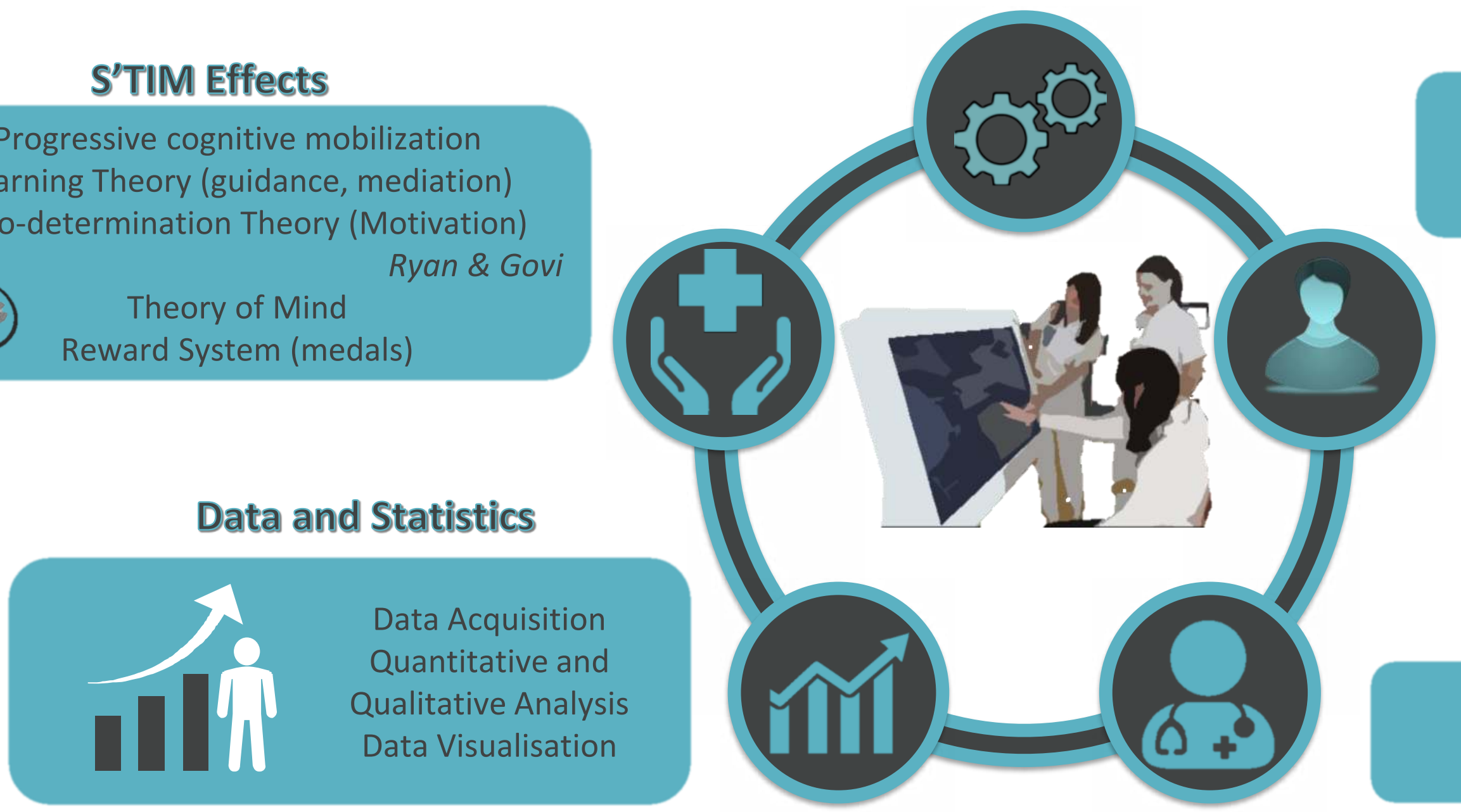

\section{Consequences for Patients}

Global Cognitive Stimulation (Virole \& Radillo 2010) Exercices Progression (O)

Better attention and working memory

Metacognition, strategies acquisition Self respect, self confidence, self-efficacy Socio-affective and Socio-cognitive impact Transfer of knowledges in non numeric environments

\section{Therapists Support}

Interactions with therapists
(immediate positive reinforcement)
Debriefings about used strategies

\section{TESTS}

Cognitive (GREFEX)

\section{Thymic (HAD)}

Behavior (IDSC)

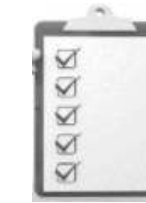

Pre-inclusion Tests (TO)

\section{Clinical Study}

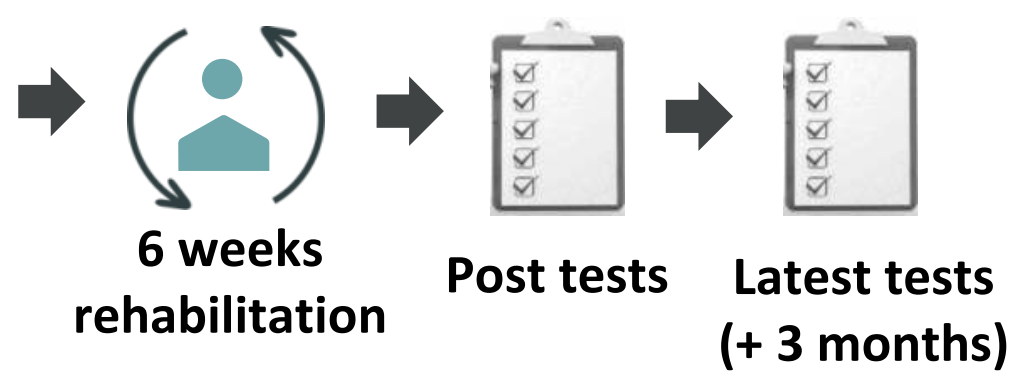

Conclusion

This new, innovating and multidisciplinary study presents high stakes for the future of patients with dysexecutive syndrome. With therapists' implication, the SG S'TIM will increase patient autonomy and transfer them at the heart of their rehabilitation and give them a chance to go back to their daily life.

\section{References}

O. Godefroy et GREFEX, « Syndromes frontaux et dysexécutifs », Rev Neurol, Paris, p. 899-909, 2004.

R. Ryan et E. Deci, « Overview of self-determination theory: An organismic dialectical perspective ", in Handbook of Selfdetermination Research, University Rochester Press, 2002, p. 3-33

J. Alvarez et D. Djaouti, Introduction au Serious Game / Serious Game: An introduction, 2e Revue et augmentée. Questions Théoriques, 2012.

P. Wouters, C. van Nimwegen, H. van Oostendorp, et E. D. van der Spek, «A meta-analysis of the cognitive and motivational effects of serious games. », J. Educ. Psychol., vol. 105, n 2, p. 249-265, 2013. 